\title{
A ESTRUTURA E O FUNCIONAMENTO DO ENSINO E A FORMAÇÃO ESCOLAR ${ }^{1}$
}

\author{
Rogério Rodrigues ${ }^{2}$
}

\begin{abstract}
RESUMO
O objetivo deste artigo é analisar a estrutura e o funcionamento do Ensino Fundamental e Médio para além da compreensão comum que se faz no campo educacional. Partimos da hipótese de que a organização da unidade escolar se constitui também no conjunto das relações humanas, para além de aspectos objetivos presentes nas determinações das leis educacionais. O método utilizado tem como proposição investigativa a teoria crítica na interpretação e análise dos fundamentos filosóficos da estrutura e funcionamento do ensino. Os resultados indicam que, na área da educação escolar, a legislação escolar encontra-se dentro do jogo que se produz na interface entre os sujeitos, na legalidade e na legitimidade instituídas por um não saber, mas que opera como ajuste no ordenamento da unidade escolar. Conclui-se que as práticas institucionais escolares podem ser interpretadas como a forma política da organização da unidade escolar como algo que adere à legitimidade e resulta em ações, quando os sujeitos buscam a Lei e, principalmente, quando são submetidos à autoridade. Toda a estrutura e funcionamento da unidade escolar deveriam pautar-se numa gestão democrática, e, principalmente, deveriam dar voz a todos aqueles que têm algo a dizer sobre o seu modo de existir e pensar no campo da cultura.
\end{abstract}

Palavras-chave: Organização escolar. Gestão educacional. Legislação educacional.

\section{THE STRUCTURE AND OPERATION OF THE EDUCATION AND THE SCHOOL FORMATION}

\begin{abstract}
The objective of this article is to analyze the structure and functioning of elementary and high school beyond the common understanding that is made in the educational field. We start from the hypothesis that the organization of the school unit is also constituted in the set of human relations, in addition to objective aspects present in the determinations of educational laws. The method used has as an investigative proposition the critical theory in the interpretation and analysis of the philosophical foundations of the structure and functioning of teaching. The results indicate that, in the area of school education, the school legislation is within the game that is produced at the interface between the subjects, in the legality and legitimacy instituted by a not knowing, but that operates as an adjustment in the ordering of the school unit. It is concluded that school institutional practices can be interpreted as the political form of the organization of the school unit as something that adheres to legitimacy and results in actions, when subjects seek the Law and, especially, when they are submitted to authority. The whole structure and functioning of the school unit should be based on democratic management, mainly it should give voice to all those who have something to say about their way of existing and thinking in the field of culture.
\end{abstract}

Keywords: School organization. School management. Educational law.

RECEBIDO EM: 26/6/2018

ACEITO EM: 30/3/2020

\footnotetext{
1 Agradecimento à Universidade Federal de Itajubá (Unifei) e aos alunos da Licenciatura do segundo semestre de 2018 na disciplina Estrutura e Funcionamento do Ensino Fundamental e Médio.

2 Universidade Federal de Itajubá (Unifei). Av. BPS, 1.303-37500-903-Pinheirinho, Itajubá/MG, Brasil. http://lattes.cnpq.br/3509356707584426. http://orcid.org/0000-0003-2657-7302. rrunifei@hotmail.com
} 


\section{A UNIDADE ESCOLAR COMO LUGAR ESPECÍFICO PARA FORMAÇÃO DO SUJEITO}

$\mathrm{Na}$ unidade escolar os diversos componentes curriculares segmentados parecem conduzir o processo de ensino e aprendizagem como se fosse uma linha de montagem, em que diversos pedaços de conteúdos juntos podem compor a grade curricular e, principalmente, promover o processo formativo do sujeito.

Esse modelo educacional, de forma segmentada, tem promovido a desqualificação do saber científico no campo da cultura escolar, pois o aluno não adquire a capacidade associativa dos conceitos. Isso apresenta-se na falta de associação entre os conteúdos e torna-se o verdadeiro paradoxo da estrutura curricular escolar, que se fundamenta numa linha de continuidade, seguindo um modelo de hierarquia, em que todo conhecimento possui uma raiz matriz do conhecimento, que vai se ramificando em diversas áreas do saber - o modelo da árvore.

É curioso como a árvore dominou a realidade ocidental e todo o pensamento ocidental, da botânica à biologia, a anatomia , mas também a gnosologia, a teologia, a ontologia, toda a filosofia...: o fundamento-raiz, Grund, roots e fundations (DELEUZE; GUATTARI, 2014, p. 38).

Em contrapartida, pode-se afirmar que a melhoria na qualidade do ensino seria a constituição de outra concepção sobre o saber, em que o conhecimento pudesse interligar simultaneamente diversos modos de saber, sem nenhuma estrutura de hierarquia. $O$ atual governo brasileiro trabalha no sentido de buscar medidas que invertam essa lógica-raiz, a fim de criar condições de estabelecer outra concepção de ensino, mas o que prevalece é a segmentação, uma vez que

A escola não é a única instituição responsável por garantir esses direitos, mas tem um papel importante para que eles sejam assegurados aos estudantes. Para que possa cumprir este papel, ao longo da educação básica serão mobilizados recursos de todas as áreas de conhecimento e de cada um de seus componentes curriculares de forma articulada e progressiva, pois em todas as atividades escolares aprende-se a se expressar, conviver, ocupar-se da saúde e do ambiente, localizar-se no tempo e no espaço, desenvolver visão de mundo e apreço pela cultura, associar saberes escolares ao contexto vivido, projetar a própria vida e tomar parte na condução dos destinos sociais (BRASIL, 2015).

Compreende-se que a unidade escolar deveria ser organizada de forma a atender à formação do trabalhador, no sentido amplo de permitir-lhe ter plena capacitação e apoderar-se de habilidades intelectuais e manuais, para que possa inserir-se criticamente no mundo do trabalho.

Parte-se da hipótese de que o impedimento da realização dessa tarefa formativa crítica esteja relacionado ao modo como o sistema educacional brasileiro organiza-se, ou seja, basicamente em duas etapas - na Educação Básica e no Ensino Superior (BRASIL, 2016) -, e isso apresenta uma falta de conjunção entre as metas e finalidades desses dois sistemas de ensino. Esse modelo sem conjunção e terminal, entretanto, acaba por atender à lógica da reprodução do capital, pois a baixa qualificação da formação tende a desvalorizar o baixo valor da força de trabalho. 
A perda de sentido no papel do sistema escolar interfere diretamente na evasão escolar, pois grande parte dos sujeitos, por não encontrar, no processo de escolarização, o caminho para a cidadania, acaba por ingressar na economia informal ou em empregos de baixa qualificação.

Neste caso, na organização e na estrutura do ensino brasileiro ocorrem vários fenômenos que afetam a formação do sujeito para atuar no campo do trabalho, e nesse conjunto optou-se por focar em três ocorrências: 1) A evasão escolar; 2) A educação básica como processo final na formação do trabalhador; e 3) A precarização no Ensino Superior. Para se pensar esse processo de formação do trabalhador, portanto, propõe-se, a seguir, a análise sobre o referido tema no campo de estudo próprio dos fundamentos filosóficos da educação, no sentido de resgatar o sentido da palavra educar como algo que esteja propriamente relacionado ao significado de cuidados na formação do sujeito no campo da cultura.

Tradicionalmente, quando se fala na organização escolar na educação básica, referimo-nos à estrutura e funcionamento do Ensino Fundamental e Médio, e a compreensão comum que se faz, no campo educacional, é de que serão abordadas somente as questões referentes à legislação escolar. Partimos do pressuposto de que essa interpretação da estrutura e funcionamento da unidade escolar, pautada, exclusivamente, nas leis educacionais, em grande parte corresponde ao elemento verdadeiro para se compreender a instituição escolar, pois permite interpretar diretamente a lógica de trabalho presente e a organização e funcionamento desse trabalho. A rotina escolar e suas especificidades encontram-se determinadas por questões práticas, por exemplo, dias letivos, carga horária, disciplinas obrigatórias, enfim, um conjunto de determinações no campo da legislação escolar que define o modo de existir do cotidiano no ambiente escolar.

Ocorrem, entretanto, outros fatos, também estruturais na unidade escolar, que alteram ou mantêm seu funcionamento e cujas determinações encontram-se para além das leis que modificam as determinações no campo da organização das práticas organizacionais. Nesse contexto, compreendemos que acontece um paradoxo no âmbito do funcionamento escolar da legislação escolar: de um lado esta transparece possuir certa materialidade operante no campo da legislação educacional, e, por outro, sua execução passa por um filtro, que são os sujeitos que ali se encontram bem como suas práticas educativas, que interferem no modo de fazer a rotina escolar. Ao intelectual da área educacional caberia, portanto, perguntar: Quais são os elementos da lei que definem sua legitimidade no conjunto estruturante do funcionamento da rotina instituída no ambiente escolar?

Esse questionamento acerca das determinações da lei permite compreender o que "funciona" e o que "não funciona", no ambiente escolar, como elementos de adesão ou resistência. Em outras palavras, diria que a lei "pega" ou "não pega", em decorrência de um não saber que nos interessa investigar acerca da estrutura e funcionamento como conceito filosófico para se interpretar os determinantes do real no campo educacional. Desse modo, os elementos da legitimidade, que pouco se discute no cam- 
po da "estrutura e funcionamento da educação", teria a raiz no próprio conceito de estrutura e funcionamento, como categorias filosóficas que auxiliam na compreensão do modo operante de vida do sujeito em interface com a unidade escolar.

Partimos, portanto, da compreensão quase incomum de que, na área da educação escolar, tudo gira em torno do jogo de interesses que se produz na interface entre a legalidade e a legitimidade da legislação escolar, instituída por um não saber, mas que opera como ajuste daquilo que pega e aquilo que não pega em termos de ordenamento do funcionamento da unidade escolar. Nesse sentido, torna-se passível de compreender que seria correto interpretar as determinações regimentais como elementos que atingem diretamente a forma política da organização da unidade escolar como algo que adere à legitimidade, e é possível compreender também o quanto os sujeitos implicam a Lei e, principalmente, a autoridade. Percebe-se, então que a organização da unidade escolar não é nada semelhante ao funcionamento de uma fábrica em que se junta peças (conteúdos) para montar o processo formativo do sujeito. O campo das relações humanas no ambiente escolar, portanto, deveria transparecer situações adversas que, no processo de transmissão do saber, constitui-se na arte de fazer coisas em que os sujeitos compartilham seus conhecimentos.

\section{PROCEDIMENTOS METODOLÓGICOS INVESTIGATIVOS NA COMPREENSÃO DA ESTRUTURA E O FUNCIONAMENTO DA ESCOLA}

Partimos da compreensão de que a falência no campo educacional gira em torno de conceber a unidade escolar como algo que opera nas relações entre a estrutura enrijecida e o funcionamento dinâmico e instituído pela lógica do mercado, em que o aluno é concebido como cliente e a educação como produto. Toda reforma educacional repete o mesmo ao afirmar uma novidade em termos de mudança, como qualidade para atender a uma demanda de sucesso, mas sem a diferença de se alcançar o centro do fazer do processo educativo, que opera no interior do aparelho escolar, mais propriamente na sala de aula, como lugar de transmissão da cultura.

Essa condição de se reduzir a organização do trabalho escolar a algo simples, de ajuste e adaptações, seria a impertinente semelhança desta com uma fábrica em que a montagem com qualidade se reduz à obediência do projeto pedagógico. Essa semeIhança entre a unidade escolar e a fábrica significa que, de um lado, tudo pode funcionar mecanicamente, e, de outro, tudo em seu interior precisa de ajustes, como na expressão popular que se ressalta que o problema da educação é a capacitação dos professores. Isso apresenta-se como verdadeiro paradoxo, pois o processo de formação do sujeito é algo diretamente relacionado com a capacitação, mas o mesmo deveria ser posicionado como intelectual, que se apresenta reflexivo em seu modo de atuar em sala de aula. Compreendemos, todavia, que nada se resolve em termos de qualidade na educação enquanto os autores do processo educativo forem posicionados como objetos e, portanto, no caso do aparelho escolar, como lugar do nada e da distração pautada na futilidade daquele que se representa como aplicador do conteúdo para os seus alunos.

O método investigativo utilizado para se analisar esses determinantes da organização escolar tem como proposição a teoria crítica na interpretação e análise dos fundamentos filosóficos da estrutura e funcionamento do ensino. Nesse caso, pensar 
a unidade escolar no campo do conceito de estrutura e funcionamento, requer compreendê-la como um elemento interligado a ações reflexivas do sujeito que se encontra entre a representação do aparelho escolar e dos próprios determinantes do processo educativo na transmissão do conceito no campo da cultura escolar.

A escola como aparelho possui uma dinâmica de funcionamento que pode se assemelhar com uma fábrica, mas o que a distingue da mesma é que os seus processos internos de montagem envolvem a experiência do pensamento na condição de estabelecer uma leitura crítica da realidade.

Para se compreender o processo formativo do sujeito nesta montagem que ocorre dentro da unidade escolar, não se pode deixar de a associar ao conceito de estrutura em que podemos remeter a Louis Althusser, que a vê como um elemento simples, em que

Qualquer pessoa pode compreender facilmente que esta representação da estrutura de toda sociedade como um edifício que comporta uma base (infraestrutura) sobre a qual se erguem os dois "andares" da superestrutura, é uma metáfora, muito precisamente, uma metáfora especial: uma tópica. Como todas as metáforas, esta sugere, convida a ver alguma coisa. O quê? Pois bem, precisamos isto: que os andares superiores não poderiam "manter-se" (no ar) sozinhos se não assentassem de facto na sua base ([1970?], p. 26-27).

A montagem que ocorre na unidade escolar associada ao conceito de estrutura do aparelho escolar, trata-se do processo formativo que organiza todo o seu funcionamento como uma verdadeira bricolage que ocorre em seu todo, à qual o sujeito fica subordinado ao acaso de

[...] um plano preconcebido e se afastam dos processos e normas adotados pela técnica. Caracteriza-o especialmente o fato de operar com materiais fragmentários já elaborados, ao contrário, por exemplo, do engenheiro que, para dar execução ao seu trabalho, necessita da matéria-prima (AGUIAR; SOUZA, 1989, p. 32).

Pensar a educação na perspectiva da bricolage, portanto, seria compreender que no fazer educativo algo escapa ao planejar a formação do sujeito. A relação humana que constitui a trama da formação de um sujeito é regida, para o desespero de alguns, pelo inesperado. É sobre esse inesperado que precisamos nos debruçar, para pensarmos uma pedagogia, à qual denominaremos de pedagogia do caos, como uma aparente desordem dos fatos educativos, em contraposição a uma pedagogia da norma. ${ }^{3}$

Partimos do pressuposto de que, em grande parte, o denominado projeto pedagógico, no campo escolar, seria a tentativa de controlar algo que, pela própria condição, no campo das relações humanas, não se torna passível de controle. Desse modo, o próprio conceito de funcionamento também transparece como uma concepção de mundo na forma de compreender o processo de escolarização.

\footnotetext{
Mantemos o termo a pedagogia da norma, apesar da redundância, pois as teorias educacionais são estritamente normatizadoras sobre como o educador deve proceder para que a relação de ensino e aprendizagem seja eficiente. Assim, as palavras caos e norma apontam, em termos de teorias educacionais, para perspectivas diferentes de como pensar a atividade educativa.
} 
Nessa amarração ou embaraço entre o processo formativo, a estrutura da unidade escolar e a concepção do seu funcionamento, pode se compreender a unidade escolar como elemento que resulta com a aplicação da norma, mas a "[...] regra não é apenas uma maneira habitual de agir; é, antes de mais nada, uma maneira de agir obrigatória, isto é, que escapa, em certa medida, do arbítrio individual" (DURKHEIM, 1999, p. IX-X) em todos aqueles que ali se encontram presentes e acabam se tornando participantes da estrutura e funcionamento da unidade escolar.

Nesse sentido é que podemos definir a interpretação da estrutura e o funcionamento como o divisor de águas entre os processos educativos que atravessam o sujeito na emancipação ou no embrutecimento, que se estabelecem no modo como ele se insere no campo da cultura em interface com o aparelho escolar.

A compreensão desses modos operantes do aparelho escolar permite a ruptura com o senso comum e o surgimento da autoridade do gestor escolar na interpretação da legislação escolar em instituir o modo de fazer as coisas, que se encontra em seu interior (escola), para a formação do sujeito no campo da cultura.

\section{RESULTADOS E DISCUSSÃO - PARA ALÉM DA FORMAÇÃO DO SUJEITO NO PARADIGMA PAUTADO NA CAUSA E EFEITO}

Para iniciarmos essa discussão sobre a presença do sujeito, que expressa a legitimidade da lei perante a estrutura e o funcionamento, podemos considerar que os anos iniciais da formação escolar tornam-se fundamentais para a constituição reflexiva do pensamento crítico do mesmo perante o real.

Nesse termo, pergunta-se: Quem educa o educador? Essa pergunta remete à compreensão de que, em se tratando da formação do licenciado como especialista em assuntos educacionais, este seria aquele que responsável em interpretar as dinâmicas internas do campo escolar para além do senso comum.

Compreendemos que a unidade escolar não é uma unidade e, portanto, apresenta uma complexidade que agrega uma mistura de pensamentos e concepções sobre o processo formativo. A escola pública seria uma tentativa, numa determinada concepção da unidade, que agrega a diversidade e, portanto, possui uma grande riqueza em seu interior, pois tudo que ali acontece deveria funcionar com o princípio de igualdade plena entre todos os sujeitos, independente de classe social de origem. Neste caso, o gestor educacional apresenta-se como uma peça-chave e torna-se ainda mais decisivo seu papel na compreensão da complexidade do assunto, pois deveriam assumir a posição de mediadores e constituir-se como intelectuais ao proferir e permitir a circulação da palavra organizacional para o outro, no sentido de colaborar com os elementos que orientam a atividade escolar para além dos determinantes da legalidade na estrutura e funcionamento.

Em relação à estrutura e funcionamento da unidade escolar, pela ótica do espaço público, propõem-se, em termos organizacionais, que seja comum a todos e não exclusiva à particularidade de algum grupo ou segmento de classe social. Essa condição reflexiva do sujeito no campo da administração escolar é de fundamental importância para a organização do ambiente escolar como dispositivo que cumpre a função de lugar 
para a transmissão do saber, que se encontra em interface com outros determinantes no campo da estrutura e funcionamento da unidade escolar. A unidade escolar não é uma propriedade particular que atende aos interesses de um pequeno grupo, mas um espaço de exercício de cidadania no qual se vive em coletividade e, portanto, deve atender aos interesses comuns a todos.

$\mathrm{Na}$ contraposição desta questão do interesse particular e aquilo que é comum a todos e, em se tratando do processo formativo do licenciado, torna-se possível observar a presença e, principalmente, a necessidade pedagógica de diversas disciplinas do curso que focam nos denominados exercícios pedagógicos, que instituem o modo operante do aprender pautado na metodologia de ensino, que, em grande parte, direciona-se ao reducionismo para atender a aspectos formativos para o denominado mercado do trabalho. Em regra, essas disciplinas curriculares são normatizadas pela legislação escolar da área formativa do licenciado, e, segundo a Resolução do Conselho Nacional de Educação (CNE) de 4 de março de 2002, fica determinada a seguinte distribuição de carga horária:

Art. 10 A carga horária dos cursos de Formação de Professores da Educação Básica, em nível superior, em curso de licenciatura, de graduação plena, será efetivada mediante a integralização de, no mínimo, 2800 (duas mil e oitocentas) horas, nas quais a articulação teoria-prática garanta, nos termos dos seus projetos pedagógicos, as seguintes dimensões dos componentes comuns: I - 400 (quatrocentas) horas de prática como componente curricular, vivenciadas ao longo do curso; II - 400 (quatrocentas) horas de estágio curricular supervisionado a partir do início da segunda metade do curso; III - 1800 (mil e oitocentas) horas de aulas para os conteúdos curriculares de natureza científico e cultural; IV - 200 (duzentas) horas para outras formas de atividades acadêmico-científico-culturais. Parágrafo único. Os alunos que exerçam atividade docente regular na educação básica poderão ter redução da carga horária do estágio curricular supervisionado até o máximo de 200 (duzentas) horas (p. 9).

Nesse longo processo, o professor é formado para trabalhar numa unidade escolar cuja determinação altera-se em alguns aspectos em decorrência da escolha para atuar numa adversidade, em que a cultura escolar encontra-se subordinada aos determinantes do mercado, atingindo diretamente seu eixo organizativo da rotina escolar. A própria reforma atual do Ensino Médio apresenta-se como exemplo dessa situação, em que o discurso da competência profissional atinge diretamente a organização do ensino nesse segmento escolar que assume como proposição fundamental o atendimento a aspectos da profissionalização do sujeito.

Essa profissionalização precoce apresenta-se com objetivos claros de retirada do sujeito do processo formativo mais radical, que, possivelmente, se encontraria no Ensino Superior, uma vez que, com essa mudança,

A reforma do ensino médio é uma mudança na estrutura do sistema atual do ensino médio. Trata-se de um instrumento fundamental para a melhoria da educação no país. Ao propor a flexibilização da grade curricular, o novo modelo permitirá que o estudante escolha a área de conhecimento para aprofundar seus estudos. A nova estrutura terá uma parte que será comum e obrigatória a todas as escolas (Base Nacional Comum Curricular) e outra parte flexível. Com isso, o ensino médio apro- 
ximará ainda mais a escola da realidade dos estudantes à luz das novas demandas profissionais do mercado de trabalho. E, sobretudo, permitirá que cada um siga o caminho de suas vocações e sonhos, seja para seguir os estudos no nível superior, seja para entrar no mundo do trabalho (BRASIL, 2017).

Essa circunstância da longa jornada formativa do licenciado (futuro professor) e as alterações do funcionamento da unidade escolar para a profissionalização, fazem com que estabeleçamos, como hipótese de trabalho, que a estrutura e o funcionamento da unidade escolar se estabelecem entre dois elementos fundamentais, quais sejam: no (des)encontro entre os sujeitos, que, de um lado, prevalece numa concepção a priori do que seja educar o sujeito, concebida nos cursos de formação do licenciado nas metodologias de ensino, numa concepção de causa e efeito; e, de outro, nas condições objetivas presentes na instituição escolar que se encontram determinadas com as rotinas estruturantes do fazer educativo, que condiciona todo o funcionamento da unidade escolar para atender a uma lógica de mercado na precoce profissionalização dos sujeitos.

Compreendemos que, em grande parte, o fazer educativo encontra-se inserido numa tradição da própria unidade escolar, em que os componentes das disciplinas pedagógicas se apresentam na sequência de exercícios didáticos próprios para a aprendizagem do aluno. Esses exercícios do ensinar possuem o caráter universal de ensinar tudo a todos como uma inspiração para instrumentalizar o aluno do curso de Licenciatura no campo da didática, e isso, pode-se afirmar, possui um argumento público no tratamento da transmissão do saber. Não podemos nos esquecer, portanto, que, no campo pedagógico, a didática inaugurada por Coménio tem como subtítulo: "tratado da arte universal de ensinar tudo a todos" (COMÉNIO, 1985).

Essa propriedade educativa, no princípio de educar tudo e a todos, tem como proposição básica a transmissão universal do conhecimento do simples para, depois, chegar ao complexo, e isso acaba por se constituir na fórmula educativa que, por vários anos, se estabeleceu como paradigma da formação escolar, anunciada como a metodologia de ensino, que também organiza toda a estrutura curricular da unidade de ensino. A estrutura e o funcionamento da unidade escolar, pelo viés do princípio de realidade, contudo, indicam outra resultante dessa função de causa e efeito no processo educacional, ou seja, o ato de ensinar tudo a todos tem se apresentado como o ensinar pouco a todos. Os próprios dados oficiais indicam a falência no processo formativo como uma regressão do pensamento científico, e isso já pode ser constatado diretamente nos exames oficiais do governo.

[...] resultados do Pisa 2015, mais importante exame educacional do mundo, elaborado a cada três anos pela Organização para a Cooperação e Desenvolvimento Econômico (OCDE) com o intuito de aferir a qualidade, equidade e eficiência dos sistemas escolares, mostraram mais uma vez os alunos brasileiros nas últimas posições do ranking. [...] Entre as 72 nações, o relatório mostrou o País na 63a posição em ciências, na 59a em leitura e na 66a colocação em matemática. Em ciências, os alunos brasileiros obtiveram 401 pontos contra 493 pontos da média da OCDE, em leitura, 407 pontos ante 493, e em matemática, 377 pontos contra 490 (PAIVA, 2017). 
Fica em evidência que os indicadores do Programme for International Student Assessment (Pisa - Programa Internacional de Avaliação de Estudantes) apontam para o curto-circuito que se apresenta na condição do aprendiz sem aprendizagem e que impede a inserção do sujeito para o campo da cultura. Essa condição de falência no processo formativo acaba servindo de justificativa para as alterações na organização escolar, pois

A edição da Medida Provisória (MP) seguiu rigorosamente as exigências previstas na Constituição Federal. Em primeiro lugar, em decorrência da urgência do problema desse nível de ensino no país, dados do IDEB recém-divulgados mostram uma realidade trágica no ensino médio e retratam a urgência da reforma. Em segundo lugar, em consequência da relevância do tema que se apresenta na medida em que o fracasso do ensino médio brasileiro é um dado da realidade, como demonstram os resultados das avaliações nacionais e internacionais. As propostas da MP são fruto do amplo debate acumulado no país nas últimas décadas, o que permitiu ao governo acelerar a reforma (BRASIL, 2017).

De modo geral, os educadores acabam sofrendo por todos os lados e destituem-se da posição de intelectuais e responsáveis pela falência do processo formativo. A unidade escolar acaba viciando-se e, principalmente, contagiando-se da forma de agir, em que diversos professores reproduzem um modo operante de trabalho pautado na correta metodologia de ensino explicativa, e outro que não sabe deve ser esclarecido do conteúdo pelo "mestre explicador", mais propriamente o ressurgimento do embrutecimento explicador, pois ocorre "[...] embrutecimento quando uma inteligência é subordinada a outra inteligência" (RANCIÈRE, 2002, p. 31).

A condição de "mestre explicador" (RANCIÈRE, 2002) é alimentada pela própria estrutura e funcionamento da instituição escolar como a qualidade do programa de ensino, em que a grade curricular se organiza numa função lógica de se transmitir o conteúdo do mais fácil para, depois, se atingir o mais difícil. Essa condição cronológica do conteúdo atinge o centro do pensamento abstrato e constitui uma fórmula que somente podemos conhecer quando estamos preparados por outro sujeito, supostamente mais inteligente, que declara: “[...] que agora você está pronto para aprender [...]" e

[...] ele decreta o começo absoluto - somente agora tem início o ato de aprender; por outro lado, ele cobre todas as coisas a serem aprendidas desse véu de ignorância que ele próprio se encarrega de retirar. Até ele, o pequeno homem tateou às cegas, num esforço de adivinhação. Agora, ele vai aprender (RANCIÈRE, 2002, p. 23-24).

No campo do exercício pedagógico, em sala de aula, muitas vezes, repete-se o mesmo que foi ensinado no dia, semana ou ano anterior, e isso fica determinado como o passar o ponto do "mestre explicador" (RANCIÈRE, 2002) e, portanto, este deve ser copiado por todos os alunos como se se constituísse a prática educativa de ensino e 
aprendizagem como algo que se assemelha ao funcionamento e estrutura da unidade escolar, tal qual um dispositivo operante, em que o aluno deve apenas atender às diversas demandas dos fazeres - a lição de casa. ${ }^{4}$

Parece que todo ano escolar começa e acaba sempre do mesmo modo: controlar a presença dos alunos; apresentação do plano do curso; passar o ponto e definição do modo de avaliar os alunos e, no final, constatar que poucos, ou quase ninguém, compreendem o que foi transmitido no campo do saber.

Nessa relação de ensino, fiquei, muitas vezes, perguntando-me se não existiria algo diferente para se produzir neste contrato estabelecido para a transmissão do saber como verdadeiro contato com a cultura, em que o ensino e a aprendizagem pudessem apresentar algum sentido entre o pensamento e a prática. Neste sentido, compreendemos que o professor, ao anunciar o conceito para o aluno, repete o que lhe foi transmitido. O ensinar, entretanto, não se reduz a repetir palavras, ou seja, trata-se de ampliar criticamente a compreensão do conceito com outros diversos significantes no paradoxo da repetição e diferença em que toda a estrutura e funcionamento da escola pode colaborar com está proposição da tarefa educativa.

Por que refiro-me a paradoxo como repetição e diferença da estrutura e funcionamento? Porque ao se fazer o mesmo como repetição não se pode controlar os seus resultados, e isso possibilita também fazer o diferente. O que se deve evitar é acreditar na compreensão de que, pelo simples fato de que tudo fica parecido ao modelo reduzido de se passar o ponto, os alunos deveriam somente ficar repetindo a mesma coisa que o professor afirma como verdade absoluta - mestre explicador (RANCIÈRE, 2002).

Esse tipo de aproximação com o saber, sem o trabalho do pensamento crítico, torna o ambiente escolar empobrecido e destituído de qualquer sentido de criação nas atividades. No campo do senso comum, quando isso ocorre no início da educação básica, é algo supostamente aceitável, pois se explica que o sujeito se encontra em processo de adaptação com a rotina da escola nas dinâmicas da estrutura e funcionamento. 0 grande problema é quando esse modelo de ausência do trabalho do pensamento crítico também prevalece na Graduação e na Pós-Graduação, e isso interfere diretamente no trabalho da transmissão da ciência no campo da cultura escolar.

No campo da cultura escolar, a crítica da repetição destituída de sentido, aproxima-nos das ideias de Leandro de Lajonquière (2009), ao analisar a proposição de "Como a escola pode virar uma pizzaria" (LAJONQUIÈRE, 2009, p. 81). O autor compreende que a repetição sem sentido, no campo escolar, encontra-se diretamente relacionada à desarticulação do argumento pautado na noção da autoridade, pois o que se encontra em questão é como o sujeito posiciona-se perante a Lei que interdita o gozo do outro; portanto, o funcionamento da estrutura escolar assim opera:

Sobre o fato de copiar a lição em sala de aula, avalia-se que isso acaba constituindo-se em algo completamente obsoleto, pois, segundo um professor de matemática, hoje os alunos estão tirando foto do quadro de anotações do professor com seus smartfones e, portanto, perdem por completo o sentido do registro gráfico das anotações. 
[...] como um simples gesto evita que na escola nem tudo acabe em pizza. Pernoitando num vilarejo da região da Bretagne na França, assistimos ao telejornal do dia. A notícia: O comissário da pequena cidade decide intervir para conter a "indisciplina escolar" que, no caso, reduzia-se ao fato de uma criança ter contestado verbalmente uma professora sem muita politesse. O comissário chamou a criança e seu pai e depois de um sermão sobre "boa educação" fez que ambos assinassem uma advertência escrita. [...] Sua intervenção adultiza a criança, no lugar de infantilizá-la, como de fato se faz quando da utilização da etiqueta "imaturidade psicológica". Por outro, instaura entre a criança e a professora uma dimensão terceira que corta o tête-à-tête e, dessa forma, recoloca a escola no lugar de representante do espírito das leis da cidade (LAJONQUIÈRE, 2009, p. 89-90).

Aqui, instaura-se a diferença em afirmar algo para o sujeito que o lança na passagem para o mundo adulto, instaurando a legitimidade em ser adulto, mais propriamente compreendendo a autoridade como espaço de se assumir a palavra em nome próprio. Ao pegarmos uma carona nesse pensamento analítico de Lajonquière (2009), dialogamos com outras impossibilidades da estrutura e funcionamento do dispositivo da unidade escolar, para que "[...] nem tudo acabe em pizza" (LAJONQUIÈRE, 2009, p. 89) e para que se possa inserir e, principalmente, emergir o sujeito no campo da cultura escolar. Para tanto, compreendemos que a desarticulação da autoridade se encontra imbricada com um algo a mais, ou seja, no caso da precarização do aparelho escolar é algo que não se trata apenas do apagamento da instauração da Lei, mas da destituição da própria rotina escolar pautada numa repetição pseudoemancipadora como instauração do limite da crítica do pensamento circunscrito pela redução do conceito, que venha apenas a atender à repetição sem a diferença criativa. Queremos, portanto, retomar a ideia de "como a escola pode virar uma pizzaria" (LAJONQUIÈRE, 2009, p. 81), algo que opera na unidade entre o apagamento da Lei e a redução do pensamento crítico, com a desarticulação de toda a estrutura e o funcionamento da unidade escolar, apesar da enorme quantidade de leis que se impõem no campo escolar.

Partimos da suposição de que isso que ocorre no aparelho escolar se constitui numa perda de valor do que seria o espaço público para o encontro entre os sujeitos. Ao invés disso, os espaços públicos privatizam-se, numa lógica de mercado, para atender a outros sentidos e às novas demandas do tecido social. Essas novas demandas na formação escolar e profissional seriam aquelas que se encontram alheias à cultura, destituídas de pensamento crítico e, paradoxalmente, também devem fazer parte da estrutura e do funcionamento do social, condizente por completo com o tipo de cultura escolar não elaborada para minimamente formar o embrutecido esclarecido.

Essa condição de redução da função ampliada da legalidade da estrutura e funcionamento da escola, opera como uma forma de esconder o verdadeiro papel do apareIho escolar como lugar de encontro entre os sujeitos objetivando o diálogo no campo da cultura. Ao invés, entretanto, desse encontro verdadeiro, mediado no campo da cultura, o que se institui no ambiente escolar é a ampliação do "mestre explicador" (RANCIÈRE, 2002), que tem respostas pautadas em dogmas, uma vez que o que prevalece é a verdade absoluta no campo da cultura escolar. 
Na unidade escolar, em sua estrutura e funcionamento, o que predomina é o aspecto burocrático, que se revela no dito muito popular entre os educadores de que o professor finge que ensina e o aluno finge que aprende. Essa condição precária do aparelho escolar é que torna, de fato, a unidade escolar uma redução de sua organização interna e de seu funcionamento, algo parecido, nas palavras de Lajonquière (2009), com uma pizzaria, em que, no dito popular, apesar de todos os esforços, tudo acaba de fato em pizza ou, no caso, específico da unidade escolar, no tanto faz se o aluno aprende alguma coisa perante a cultura escolar. No caso do ensino escolar, todavia, tudo acaba em pizza significa que nada se ensina e nada se aprende e, tragicamente, buscam-se aplicar novas reformas no ensino sem se focar na raiz do problema, que seria estabelecer medidas que valorizem a função da atividade educativa do sujeito como intelectual para além da sua formação no paradigma pautado na causa e efeito.

\section{CONSIDERAÇÕES FINAIS - EDUCAÇÃO, EMANCIPAÇÃO E A TRANSMISSÃO DA CULTURA ESCOLAR}

Toda vez que ando pelas ruas de qualquer cidade, no Brasil, fica fácil constatar uma regressão no modo de vida urbano, pois as poucas praças públicas que ainda existem encontram-se com cercas e grades, e os aparelhos escolares ficaram feios com o passar dos anos, com suas janelas cheias de grades.

Em relação ao aparelho escolar, essa prevalência da arquitetura dos muros permite-me perguntar: Seriam todas essas grades, cercas e muros para os sujeitos não entrarem ou para não saírem da escola? Qual seria a intenção política de toda essa arquitetura que se instaura numa sociedade que circula em torno do medo do contato com o outro?

Nesse momento de reflexão sobre o modo de viver na cidade, realizar-se-á um pequeno desvio e pensar-se-á numa determinada especificidade das relações do sujeito com a cultura escolar ou no que podemos denominar de o processo civilizatório e inserção do sujeito no campo da cultura. Para tanto, verificamos as palavras de Freud em "Novas Conferências Introdutórias" (1932-1936), mais propriamente a Conferência XXXIV, que apresenta uma questão crucial para se pensar o sujeito e o processo de produção de si mesmo. Vamos ao texto em que este autor deixa declarado o verdadeiro papel da educação:

[...] a tarefa primeira da educação. A criança deve aprender a controlar seus instintos. É impossível conceder-Ihes liberdade de pôr em prática todos os seus impulsos sem restrição. Fazê-lo seria um experimento muito instrutivo para os psicólogos de crianças; mas a vida seria impossível para os pais, e as próprias crianças sofreriam grave prejuízo, que se exterioriza, em parte, imediatamente, e, em parte, nos anos subseqüentes. Por conseguinte, a educação deve inibir, proibir e suprimir, e isto ela procurou fazer em todos os períodos da história (FREUD, 1990, p. 147).

Desse modo, podemos interpretar que o educar, no núcleo familiar, seria o primeiro lugar desse controle de si, e o processo formativo escolar seria como uma segunda instância ou chance que tem o sujeito para lidar com a frustração. Ao tornar o espaço escolar uma passagem do núcleo familiar para o espaço público de fato. A unidade escolar apresenta-se como significante em torno da noção do território da cidade 
e, portanto, o exercício curricular, ao formar o cidadão, poderia ter algum significado se esse espaço escolar conseguir representar a condição pública dos fatos. Para tanto, toda a estrutura e o funcionamento da unidade escolar deveriam estar numa gestão também democrática, que possa fazer valer, em sua rotina, o exemplo de cidadania. Assim, espera-se que, toda vez que o sujeito entrar numa unidade escolar, possa encontrar, na sua organização do trabalho escolar, a valorização do indivíduo que pratica a formação intelectual; é isso que faz toda a diferença para que esta (escola), de modo algum, assemelhe-se a uma fábrica ou pizzaria e, portanto, o todo não é, de modo algum, a soma das partes em se tratando de grade curricular.

Não se pode educar sem ao mesmo tempo ensinar; uma educação sem aprendizagem é vazia e, portanto, degenera, com muita facilidade, em retórica moral e emocional. É muito fácil, porém, ensinar sem educar, e pode-se aprender durante o dia todo sem por isso ser educado (ARENDT, 2011, p. 246).

Nesse caso, torna-se importante compreender que a referida formação profissional, nos cursos de preparação de professor, possui alguns determinantes que se deveria poder identificar como de fato constituintes da rotina escolar no ensinar e no educar, como modalidade de educação de corpo e alma que se representa em ruptura com o

[...] mundo administrado, um sentimento de encontrar-se enclausurado numa situação cada vez mais socializada, como uma rede densamente interconectada. Quanto mais densa é a rede, mais se procura escapar, ao mesmo tempo em que precisamente a sua densidade impede a saída (ADORNO, 1995, p. 122).

O que se deveria buscar na formação dos professores seria a problematização de como transmitir o saber que possa romper com o comum e ser ressignificado pelo sujeito. Para tanto, toda a estrutura e funcionamento da unidade escolar deveria atender a aspectos formativos que permitam a todos aqueles inseridos emancipar-se perante a cultura escolar. O que, entretanto, seria emancipação?

No ato de ensinar e de aprender, há duas vontades e duas inteligências. (...) Chamar-se-á emancipação à diferença conhecida e mantida entre duas relações, o ato de uma inteligência que não obedece senão a ela mesma, ainda que a vontade obedeça à outra vontade (RANCIÈRE, 2002, p. 31-32).

O próprio dispositivo da estrutura e funcionamento da unidade escolar, no entanto, apresenta-se como impedimento para uma relação emancipadora entre os sujeitos, pois

O emancipador não é alguém que vai ao encontro das pessoas para emancipá-las. A emancipação sempre supõe um processo em que alguém quer passar e, assim, a questão é saber o que passar vai querer dizer (VERMEREN; CORNU; BENVENUTO, 2017, p. 196).

Aqui, expõe-se o verdadeiro nó nesse embaraço que se apresenta na estrutura e funcionamento ou na mentira que se anuncia em diversos planos de ensino, que seria a falsa concepção de formar o cidadão. Diria que a cidadania é o acesso a diversos bens 
da sociedade que permite ao sujeito participar da vida política e que, no caso específico da escrita, "[...] antes de ser o exercício de uma competência, o ato de escrever é uma maneira de ocupar o sensível e dar sentido a essa ocupação" (RANCIÈRE, 1995, p. 7).

Nesse espaço chamado sociedades escolarizadas há diversos aparelhos que a unidade escolar apresenta como mais um microespaço público e representativo de encontro ou desencontro entre os sujeitos, principalmente como lugar em que as pessoas possivelmente encontram-se para a vida coletiva. O estado de regressão, todavia, é algo que preocupa, como a perda da concepção de espaço público para a privatização dos lugares onde os sujeitos se encontram para atender a uma lógica de consumo, em que o saber encontra-se como produto, em que o ato de escrever passa a ser compreendido como uma ação mecânica de juntar letras e palavras e pouco importa a constituição dos sentidos das palavras.

Avaliamos que, se as reformas de ensino não atingirem, de fato, o processo formativo dos professores e alunos, numa perspectiva de valorizá-los como intelectuais, estaremos, a passos largos, destituindo por completo o papel fundamental da unidade escolar como lugar de transmissão da cultura científica, e, principalmente, na "[...] maneira de ocupar o sensível e dar sentido a essa ocupação" (RANClÈRE, 1995, p. 7).

A formação do intelectual seria o esforço educacional para se compreender que toda a estrutura e funcionamento da escola deveria se pautar numa gestão que seja democrática e que possa fazer valer sua rotina como exemplo de cidadania e, principalmente, dar voz a todos aqueles que têm algo a dizer sobre o seu modo de existir e pensar no campo da cultura.

Todo o especialista em educação deveria compreender a estrutura e o funcionamento da unidade escolar e suas interfaces no processo de transmissão da cultura para além do senso comum. Para tanto, a formação do sujeito intelectual, que atua no ensino escolar como educador, requer que este esteja implicado na construção da estrutura e do funcionamento da unidade escolar, primordialmente nas relações de ensino e aprendizagem direcionadas ao processo de emancipação do sujeito.

\section{REFERÊNCIAS}

AGUIAR, Almir de Oliveira; SOUZA, Maria Celeste da Costa. Nota dos Tradutores da 1a edição pela Ed. Nacional. In: LÉVI-STRAUSS, Claude. O pensamento selvagem. Trad. Tânia Pellegrini. Campinas: Papirus, 1989.

ADORNO, Theodor W. Educação e emancipação. Trad. Wolfgang Leo Maar. Rio de Janeiro: Paz e Terra, 1995.

ALTHUSSER, Louis. Ideologia e aparelhos ideológicos de Estado. Trad. Joaquim José de Moura Ramos. Lisboa: Editorial Presença \& Martins Fontes, [1970?].

ARENDT, Hannah. Entre o passado e o futuro. Trad. Mauro W. Barbosa. São Paulo: Perspectiva, 2011.

BRASIL. Base Nacional Comum Curricular (BNCC). Brasília: Ministério da Educação, 2015.

BRASIL. Lei de Diretrizes e Bases da Educação Nacional. Lei no. 9.394, 20 de dezembro de 1996. Disponível em: http://www.planalto.gov.br/ccivil_03/Leis/L9394.htm. Acesso em: jun. 2016.

BRASIL. Novo Ensino Médio - dúvidas. Ministério da Educação (MEC). Disponível em: http://portal.mec. gov.br/component/content/article?id=40361\#nem_01. Acesso em: 9 jun. 2017.

COMÉNIO, João Amós. Didática magna: tratado da arte universal de ensinar tudo a todos. Trad. Joaquim Ferreira Gomes. 3. ed. Lisboa: Fundação Calouste Gulbenkian, 1985.

CNE. Conselho Nacional de Educação. Resolução CNE/CP 2/2002 (Seção 1). Diário Oficial da União, Brasília, 4 mar. 2002. 


\section{\&Educaçăo}

DELEUZE, Gilles; GUATTARI, Félix. Mil Platôs: capitalismo e esquizofrenia. Trad. Ana Lúcia de Oliveira. Rio de Janeiro: Editora 34, 2014.

DURKHEIM, Émile. Da divisão do trabalho social. Trad. Eduardo Brandão. São Paulo: Martins Fontes, 1999. FREUD, Sigmund. Conferências XXXIV. In: FREUD, Sigmund. Obras completas. Trad. Jayme Salomão. Rio de Janeiro: Imago, 1990. V. XXII.

GENEST, Émile; FÉRON, José; DESMURGER, Marguerite. As mais belas lendas da mitologia. Trad. Monica Stahel. São Paulo: Martins Fontes, 2000.

LAJONQUIÈRE, Leandro de. Infância e ilusão (psico)pedagógica: escritos de psicanálise e educação. Petrópolis, RJ: Vozes, 2009.

PAIVA, Thais. Brasil mantém últimas colocações no Pisa. Carta Capital. Disponível em: http://www.cartaeducacao.com.br/reportagens/brasil-mantem-ultimas-colocacoes-no-pisa/. Acessos em: 13 abr. 2017.

RANCIÈRE, Jacques. O mestre ignorante: cinco lições sobre a emancipação intelectual. Trad. Lílian do VaIle. Belo Horizonte: Autêntica, 2002.

RANCIÈRE, Jacques. Políticas da escrita. Trad. Raquel Ramalhete. Rio de Janeiro: Editora 34, 1995.

VERMEREN, Patrice; CORNU, Laurence; BENVENUTO, Andrea. Atualidade de O mestre ignorante. Educ. Soc., Campinas, v. 24, n. 82, p. 185-202, abr. 2003. Disponível em: http://www.scielo.br/scielo.php?script=sci_arttext\&pid=S0101-73302003000100009\&lng=pt\&nrm=iso. Acesso em: 11 abr. 2017. 